\title{
PLANO DE FORMAÇÃO NO CONTEXTO DA PEDAGOGIA DA ALTERNÂNCIA
}

\author{
TRANINIG PLAN IN THE CONTEXT OF THE PEDAGOGY OF ALTERNATION \\ PLAN DE FORMACIÓN EN EL CONTEXTO DEL PEDAGOGÍA DE \\ ALTERNANCIA
}

\section{Luciane Maria Serrer de Mattos ${ }^{1}$ Maria de Lourdes Bernartt ${ }^{2}$}

\begin{abstract}
RESUMO
Este texto relata uma pesquisa realizada no contexto da Pedagogia da Alternância. O objetivo da pesquisa foi investigar como ocorre, no Plano de Formação, a articulação entre Temas Geradores, que dizem respeito aos conhecimentos vivenciais, e conteúdos previstos para o Ensino Médio de uma Casa Familiar Rural. Para tanto, o Plano de Formação produzido para as três séries do Ensino Médio foi analisado, considerando três categorias de articulação: explícita, implícita e conforme a abordagem. As análises demonstraram que os monitores da Casa Familiar Rural pesquisada produzem um Plano de Formação e procuram articular Temas Geradores com conteúdos do Ensino Médio. Contudo, esta articulação nem sempre acontece de forma explícita. A articulação entre Temas Geradores e conteúdos do Ensino Médio configura-se, portanto, no contexto em que a pesquisa foi realizada, como um desafio.
\end{abstract}

PALAVRAS-CHAVE: Educação do Campo. Casa Familiar Rural. Saberes Escolares.

\begin{abstract}
This text reports a research carried out in the context of Pedagogy of Alternation. The objective of the research was to investigate how the articulation between Generating Themes, which relate to experiential knowledge, and contents for the High School of a Rural Family Home, occurs in the Training Plan. To that end, the Training Plan produced for the three high school grades was analyzed, considering three categories of articulation: explicit, implicit and according to the approach. The analyzes showed that the monitors of the Rural Family House surveyed produce a Training Plan and seek to articulate Generative Themes with contents of High School. However, this articulation does not always happen explicitly. The articulation between Generating Themes and contents of High School is, therefore, in the context in which the research was carried out, as a challenge
\end{abstract}

KEYWORDS: Rural Education. Rural Family House. School Knowledge.

\section{RESUMEN}

Este texto contiene una investigación realizada en el contexto de Pedagogía da Alternância. Objetivo de la investigación fue buscar conocer como ocurre, no Plano de Formación, una articulación entre Temas Geradores, que define los conocimientos actuales y los contenidos para el Ensino Medio de una Casa Rural Familiar. Para tanto, se analizó el Plano de Formación producido para las tres series del Ensino Medio, teniendo en cuenta tres categorías de las articulaciones: explícitas, implícitas y como el enfoque.

\footnotetext{
${ }^{1}$ Mestre em desenvolvimento Regional e Doutoranda em Tecnologia e Sociedade pela UTFPR.

${ }^{2}$ Docente do Programa de Pós-Graduação em Desenvolvimento Regional da UTFPR.
}

\begin{tabular}{l|c|c|c}
\hline Rev. Ciências Humanas & Frederico Westphalen, RS & Vol. 19 n. 01 & jan./abr. 2018 \\
\hline
\end{tabular}

\begin{tabular}{l|l|l} 
Recebido em: 13/03/2017 & Aceito em: 20/04/2018 & Pg. 54 - 76
\end{tabular}




\section{CIÊNCIAS HUMANAS}

REVISTA DO PROGRAMA DE PÓS-GRADUAGĀO EM EDUCACĀOO

\section{(1) URI|}

El análisis mostró que los monitores de la Casa Familiar Rural buscaron un Plan de Formación y procuram articular Temas Geradores con contenidos del Ensino Medio. Sin embargo, esta articulación no sucede de forma explícita. Una articulación entre Temas Gerentes y Contenidos del Ensino Medio, está configurado, no contexto en que se haya realizado, como un desafío.

PALABRAS CLAVE: Educación Rural. Casa Familiar Rural; Conocimientos de escuela.

\section{INTRODUÇÃO}

Este texto relata uma pesquisa realizada acerca do Plano de Formação desenvolvido nas Casas Familiares Rurais que se utilizam da Pedagogia da Alternância. Este Plano é um instrumento pedagógico utilizado nesta Pedagogia para organizar os saberes que os jovens terão acesso no decorrer de sua formação. $\mathrm{O}$ objetivo da pesquisa foi investigar como ocorre a articulação entre Temas Geradores e conteúdos previstos no currículo do Ensino Médio.

A pesquisa foi realizada em uma Casa Familiar Rural (CFR) que pode ser definida como uma casa-escola, na qual os jovens estudam, alternando o tempo e o espaço, os conteúdos de formação geral e profissional, sem abandonar suas atividades na propriedade. É administrada por uma Associação de Pais e lideranças da comunidade envolvida no projeto. Utiliza como método de ensino a Pedagogia da Alternância, em que o jovem passa uma semana na CFR, em regime de internato, e uma semana no seu meio sócio familiar (ESTEVAM, 2012).

No Estado do Paraná, as CFRs funcionam em parceria com a Secretaria de Estado da Educação, a Associação Local das CFRs e a Associação Regional das Casas Familiares Rurais do Sul do Brasil Arcafar-Sul. A Secretaria de Estado da Educação é responsável, prioritariamente, pela oferta do Ensino Fundamental - anos finais e do Ensino Médio regular e profissional nos municípios paranaenses. E, desde 1991, cada CFR instalada no Paraná possui uma escola da rede estadual (escola base) responsável pela vida legal dos jovens matriculados. Além disso, a Secretaria de Estado da Educação tem cedido os professores para lecionarem as disciplinas da formação geral nas CFRs.

A Associação Local é composta por membros da comunidade em que a CFR está inserida e tem como objetivo, entre outros, representar os reais interesses da \begin{tabular}{l|c|c|c|} 
Rev. Ciências Humanas & Frederico Westphalen, RS & Vol. 19 n. 01 & jan./abr. 2018 \\
\hline
\end{tabular}

\begin{tabular}{l|l|l} 
Recebido em: 13/03/2017 & Aceito em: 20/04/2018 & Pg. 54 - 76
\end{tabular}




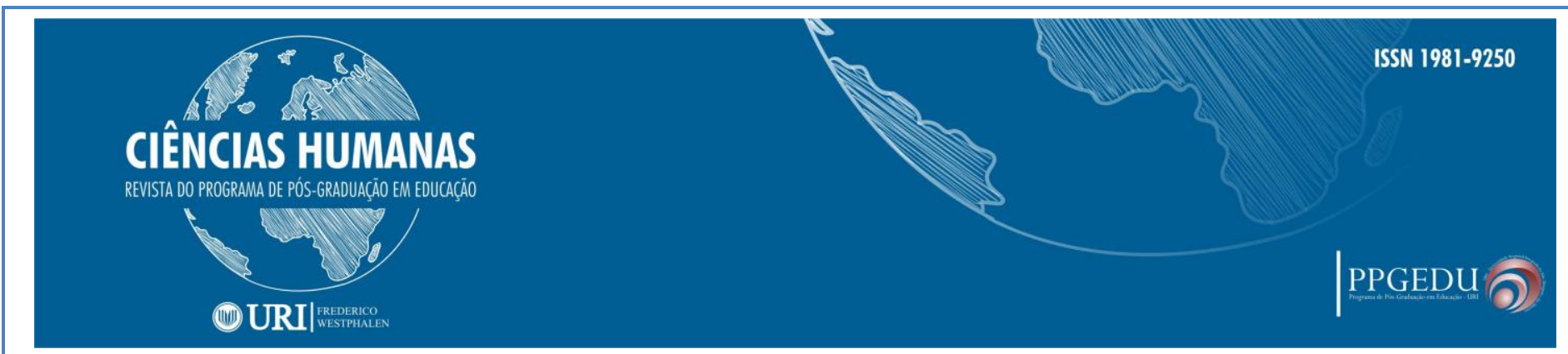

comunidade escolar, contribuindo, dessa forma, para a melhoria da qualidade do ensino, visando a formação integral dos jovens. Estevam (2012) esclarece que a Associação Local é responsável pela implantação e manutenção da CFR. Esta é formada pelas famílias dos jovens e pessoas interessadas na educação do campo e se constitui como uma entidade não governamental. Seu trabalho é feito em parceria com organizações públicas e privadas, além de receber apoio de outras entidades não governamentais que se preocupam com as questões que envolvem o campo. "O papel da associação é envolver todos os associados nas mais diversas atividades, além de coordenar toda a ação burocrática da CFR e, ainda, deve ser a responsável pelo acompanhamento na formação dos jovens" (ESTEVAM, 2012, p. 28).

E, a Arcafar-Sul está instituída como uma associação que tem como objetivo a coordenação de um trabalho filantrópico a fïm de oportunizar aos jovens agricultores a permanência no meio em que vivem proporcionando uma formação integrada com a sua realidade (ARCAFAR SUL, 2013). Ela oferece suporte à implantação, à manutenção e ao acompanhamento das CFRs, sendo responsável pela formação pedagógica de todos os monitores que trabalham nelas. Além disso, a entidade tem celebrado convênios de cooperação técnica e financeira com outras associações e órgãos públicos para a manutenção das CFRs. A Arcafar-Sul abrange municípios nos Estados do Paraná, Santa Catarina e Rio Grande do Sul; sua sede está localizada no município de Barracão, no Paraná.

Contando com esta parceria efetiva, o trabalho desenvolvido pela CFR procura articular o conhecimento dos sujeitos do campo com o conhecimento científico, por meio da alternância do tempo e do espaço. Ou seja, os jovens permanecem um período nas Casas Familiares Rurais, onde há o desenvolvimento de conhecimentos e a socialização das práticas e dos desafios, e um período aplicando os conhecimentos adquiridos, nas propriedades onde vivem junto à família.

A articulação entre conhecimento científico e popular se efetiva por meio de um método específico, o qual se vale de vários instrumentos pedagógicos. Dentre estes instrumentos, destaca-se aqui o Plano de Formação que é “a estruturação, a priori, dos 


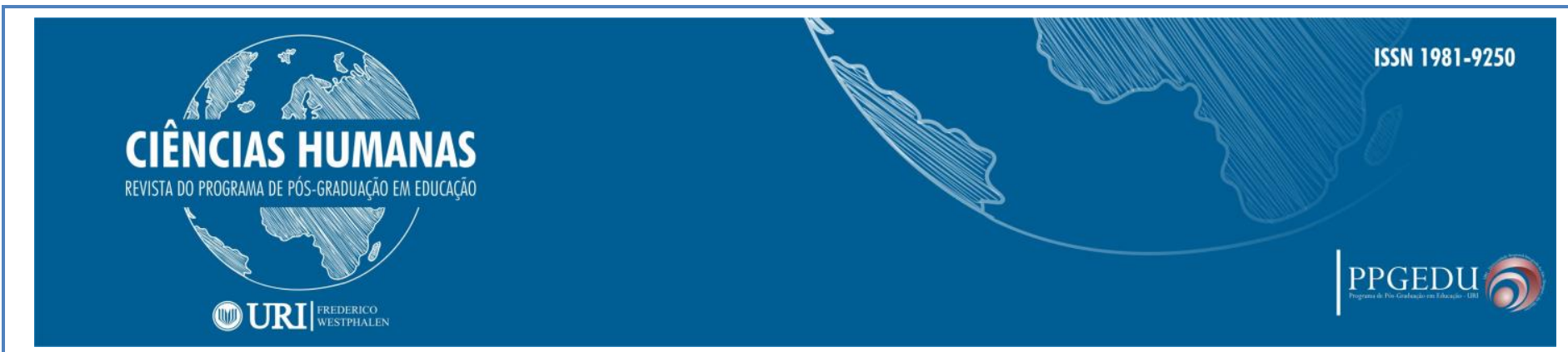

fins de formação dos jovens e define como está organizada a proposta de alternância" (ESTEVAM, 2012, p.90).

O Plano de Formação estrutura a formação que os jovens receberão na Casa Familiar Rural. Em outras palavras, o planejamento de todos os outros instrumentos pedagógicos decorre deste Plano de Formação e, ainda, este apresenta os conteúdos vivenciais, de formação geral e profissional - que os jovens terão acesso no período de formação.

De acordo com Gimonet (2007), o Plano de Formação integra os saberes dos diferentes sujeitos que contribuem para o processo e procura articular os conteúdos do programa oficial com os Temas Geradores. Estes Temas, que fazem parte da realidade vivida pelos jovens estudantes, são definidos coletivamente pela família e monitores, no início de cada ano letivo, por meio de uma pesquisa participativa. Depois de definidos os Temas Geradores por série, compete aos monitores realizar a articulação com os conteúdos previstos para cada disciplina do Ensino Médio, que no caso da CFR pesquisada estão expressos em dois documentos: Diretrizes Curriculares Estaduais da Educação Básica (2008) e Ementa do Curso Técnico em Agropecuária (2009).

Neste contexto é que surge a questão que norteou a pesquisa: Como se articulam, no Plano de Formação, Temas Geradores e conteúdos do Ensino Médio?

Para melhor entendimento do problema apresentado, é importante esclarecer que:

a) A questão parte do entendimento de que deve haver uma articulação no Plano de Formação entre os Temas Geradores e os conteúdos do Ensino Médio porque, de acordo com Gimonet (2007), o Plano de Formação integra o programa oficial e a vivência do jovem. Além disso, esta é a orientação da ARCAFAR-SUL para todas as Casas Familiares Rurais do Paraná.

b) Os conteúdos trabalhados com os jovens que cursam o Ensino Médio integrado à Educação Profissional no Estado do Paraná estão expressos nas Ementas do Cursos Técnicos e nas Diretrizes Curriculares Estaduais para a Educação Básica - DCEs (2008). Ambos os documentos orientam a construção das Propostas Pedagógicas dos estabelecimentos de ensino da rede estadual do Paraná. 


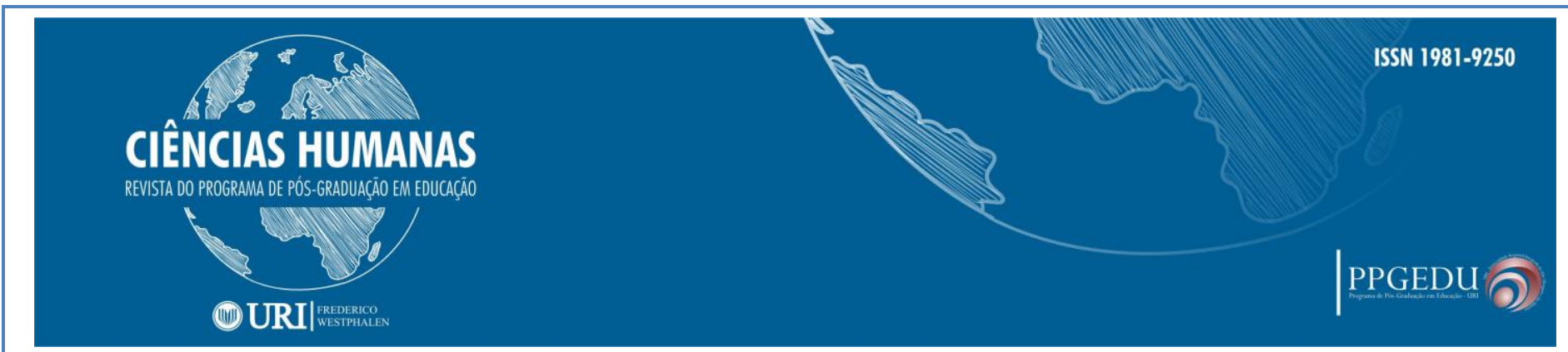

c) As DCEs (2008) assumem um currículo disciplinar, mas apontam a necessidade de os conteúdos serem tratados de modo contextualizado, estabelecendo-se relações interdisciplinares e questionando a rigidez com que tradicionalmente se apresentam.

d) As ementas das disciplinas da formação geral dos cursos profissionalizantes ofertados na rede estadual de ensino foram elaboradas tomando como referência as DCEs. Em outras palavras, as ementas apresentam o conteúdo das DCEs de forma resumida.

e) As ementas das disciplinas técnicas no Estado do Paraná foram elaboradas tomando como referência o Catálogo Nacional de Cursos Técnicos.

f) A função social da escola pública, expressa nas DCEs (2008), é a de socializar o conhecimento, pois isto é especialmente importante para os estudantes das classes menos favorecidas, que têm nela uma oportunidade, algumas vezes a única, de acesso ao mundo letrado, do conhecimento científico, da reflexão filosófica e do contato com a arte.

g) A função da Casa Familiar Rural, explicitada por estudiosos como Gimonet (2007), Marirrodriga e Calvó (2010) e Estevam (2012), é a de formar integralmente o jovem para que este contribua para o desenvolvimento do meio local. Tal formação deve ocorrer privilegiando-se os saberes que correspondem à realidade vivida pelos jovens.

Considerando este contexto, a pesquisa foi realizada na Casa Familiar Rural de Cruz Machado, localizada na região Sul do Estado do Paraná, jurisdicionada ao Núcleo Regional de Educação de União da Vitória. Esta CFR oferta somente o Ensino Médio Técnico Integrado à Educação Profissional e o curso ofertado é Técnico em Agropecuária.

Para a apresentação da pesquisa, este texto aborda, inicialmente, a organização do trabalho pedagógico na Pedagogia da Alternância, ressaltando-se o Plano de Formação neste contexto. Na sequência, a metodologia utilizada na pesquisa de campo é apresentada e análises e discussões a respeito dos dados levantados durante a pesquisa são explicitadas. 


\section{O PLANO DE FORMAÇÃO NO CONTEXTO DA PEDAGOGIA DA ALTERNÂNCIA}

Antes de se iniciar uma reflexão específica sobre o Plano de Formação é importante ressaltar que ele, assim como todos os outros instrumentos pedagógicos utilizados na Pedagogia da Alternância, caracteriza o método efetivado nos Centros Familiares de Formação por Alternância (Ceffas), os quais abarcam as Escolas Família Agrícola e as Casas Familiares Rurais. Apesar de a pesquisa ter sido desenvolvida em uma Casa Familiar Rural, manteve-se neste item a nomenclatura Ceffa, em fidelidade aos autores que discorrem sobre o Plano de Formação.

A Pedagogia da Alternância possui como objetivos, de acordo com Marirrodriga e Calvó (2010), a formação integral do jovem e o desenvolvimento local por meio da Alternância e da Associação das famílias e sujeitos locais. Vários são os elementos que compõem a Pedagogia da Alternância e que organizam o trabalho pedagógico e direcionam o processo de formação dos jovens, permitindo a reflexão nos diferentes espaços: escolar, familiar, comunitário e profissional. Gimonet (2007) afirma que a formação em alternância requer uma organização, atividades e instrumentos pedagógicos específicos para articular os tempos e espaços a fim de associar as dimensões profissionais e gerais. Para tanto, o processo de alternância deve contemplar três tempos, como mostra o quadro 1:

QUADRO 1 - Um processo de alternância num ritmo de três tempos

\begin{tabular}{|c|c|c|}
\hline $\begin{array}{l}\text { 1. } \mathrm{O} \text { meio familiar, } \\
\text { profissional, social }\end{array}$ & 2- O CEFFA & 3- $\mathrm{O}$ meio \\
\hline $\begin{array}{ll}\bullet & \text { Experiência } \\
\bullet & \text { Observações, } \\
\text { investigações, análise } \\
\bullet \quad \text { (Saberes experienciais) }\end{array}$ & $\begin{array}{l}\text { - } \\
\text { estruturação } \\
\text { - } \quad \text { Conceitualização } \\
\text { - } \quad \text { (Saberes teóricos e } \\
\text { formais) }\end{array}$ & $\begin{array}{ll}\bullet & \text { Aplicação-ação } \\
\bullet & \text { Experimentação } \\
\bullet & \text { (Saberes-ações) }\end{array}$ \\
\hline
\end{tabular}

Fonte: Gimonet (2007, p. 30)

De acordo com o autor, atividades e instrumentos pedagógicos específicos operacionalizam a Pedagogia da Alternância. Estes podem ser sintetizados da seguinte forma: 


\section{CIÊNCIAS HUMANAS}

REVISTA DO PROGRAMA DE PÓS-GRADUAC̄̄o EM EDUCAÇ̄o

(1) URI|

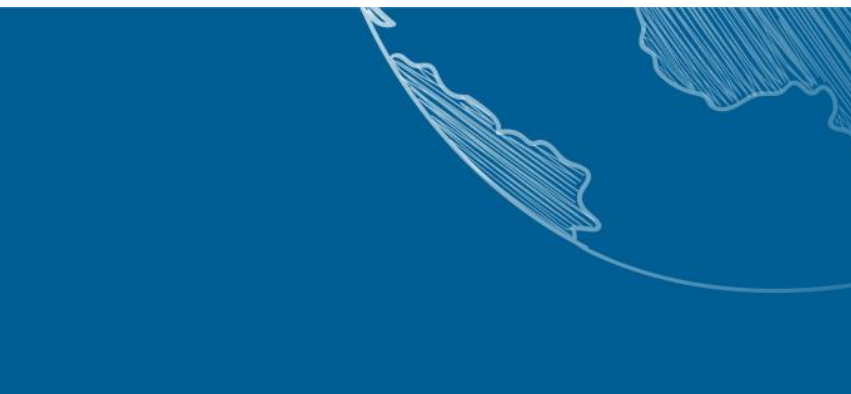

QUADRO 2 - Instrumentos Pedagógicos e sua Classificação na Pedagogia da

Alternância

\begin{tabular}{|c|c|c|}
\hline \multirow{5}{*}{ 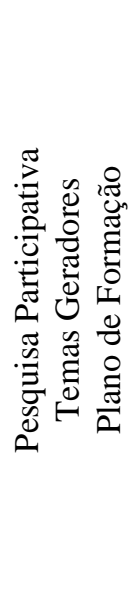 } & Instrumentos Pedagógicos & Classificação \\
\hline & $\begin{array}{l}\text { Plano de Estudos } \\
\text { Pesquisa da Realidade } \\
\text { Caderno da Realidade } \\
\text { Estágio }\end{array}$ & Instrumentos e atividades de pesquisa \\
\hline & $\begin{array}{l}\text { Atendimento Individual } \\
\text { Colocação em Comum } \\
\text { Caderno Pedagógico } \\
\text { Visita à Família }\end{array}$ & Instrumentos e atividades de comunicação/relação \\
\hline & $\begin{array}{l}\text { Visita de Estudos } \\
\text { Serão de Estudos } \\
\text { Intervenções Externas } \\
\text { Projeto Profissional de Vida do Jovem }\end{array}$ & Instrumentos didáticos \\
\hline & $\begin{array}{l}\text { Avaliação Semanal } \\
\text { Avaliação Formativa }\end{array}$ & Instrumentos de avaliação \\
\hline
\end{tabular}

Fonte: Unefab (2013).

Como se pode perceber no quadro 2, o trabalho desenvolvido na Pedagogia da Alternância parte de uma pesquisa participativa realizada na comunidade na qual o Ceffa está inserido. Tal pesquisa envolve monitores, família e lideranças da comunidade, no intuito de elaborar um diagnóstico da comunidade na qual o jovem está inserido e refletir sobre problemas e soluções possíveis. Assim, são selecionados Temas Geradores que sejam significativos e tenham relação com a vivência sócio familiar dos jovens para a construção do Plano de Formação. A partir do Plano de Formação outros instrumentos são planejados para cumprir os objetivos específicos.

Dentre os instrumentos pedagógicos apresentados, enfatiza-se o Plano de Formação, pois como afirma Gimonet (2007), a organização geral da Pedagogia da Alternância é dada por ele. O Plano de Formação representa a orquestração do conjunto dos componentes do dispositivo pedagógico. Assegura a prática da alternância, integra as finalidades do projeto educativo, enuncia os objetivos, articula os tempos, as atividades e conteúdos do campo sócio profissional com aqueles do programa oficial. Um Plano de Formação é uma ampla ordenação da coerência em torno da formação, da educação, da orientação e do desenvolvimento do jovem. 


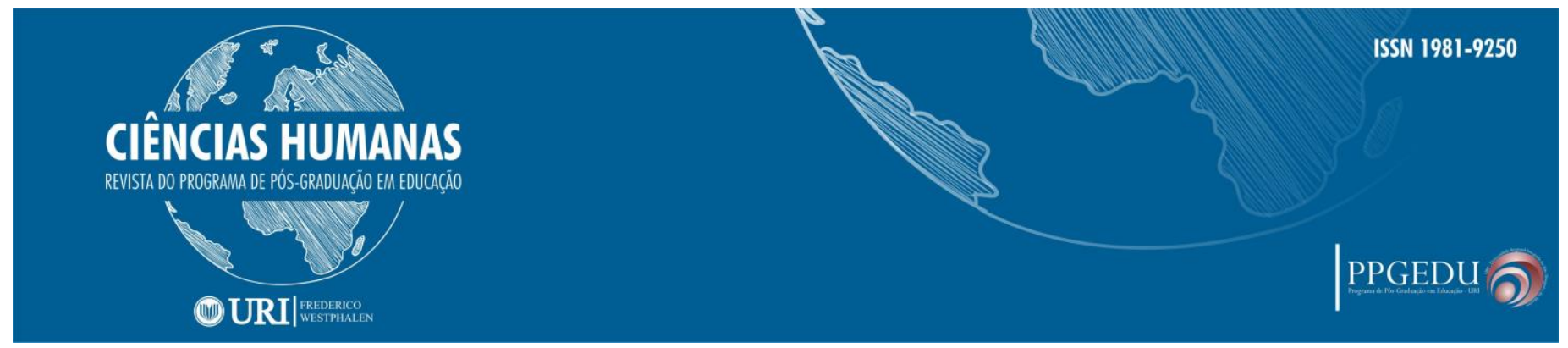

Este Plano pressupõe a preocupação com a experiência do jovem, seu contexto existencial e cultural. De acordo com Estevam (2012), o Plano de formação integra diferentes sujeitos: os jovens alternantes, monitores, familiares, parceiros, entre outros.

Ou seja, o Plano de Formação tem como objetivos articular os saberes da vida do jovem do campo com os saberes escolares do programa oficial; associar os conteúdos profissionalizantes e os conteúdos gerais; facilitar a aprendizagem dos jovens e ajudar na construção do Projeto de Vida.

O Plano de Formação estrutura o percurso formativo, conferindo-lhe um eixo diretor. Ele integra "dois programas de formação: o da vida e o da escola" (GIMONET, 2007, p.70). O autor explicita que o programa da vida oferece conteúdos informais e experienciais e o programa da escola oferece conteúdos formais e acadêmicos. Cada um desses programas possui sua lógica própria e o Plano de Formação tem como objetivo unir essas duas lógicas. A figura 1 apresenta um exemplo simplificado de um Plano de Formação:

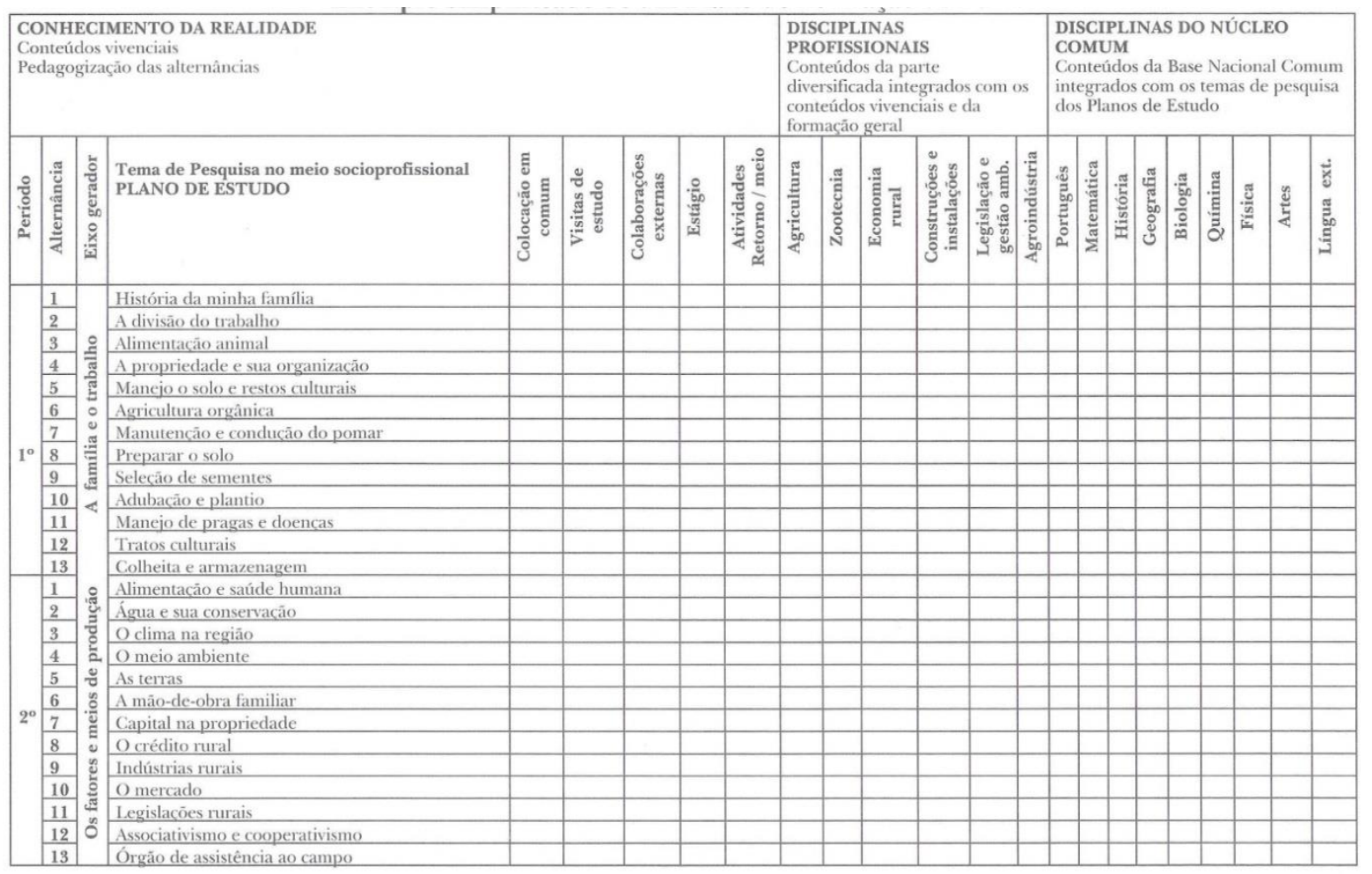

FIGURA 1 - Exemplo simplificado de um Plano de Formação dos Ceffas Fonte: Gimonet (2007, p. 75) 


\section{CIÊNCIAS HUMANAS}

REVISTA DO PROGRAMA DE PÓS-GRADUAĞ̈O EM EDUCAĞ̄o

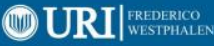

Percebe-se na figura 1 que o Plano de Formação procura articular o conhecimento da realidade do jovem com os conteúdos das disciplinas de formação geral e profissional. O Plano é organizado por período e por eixo integrador. Na figura, o Plano se refere ao primeiro e segundo período de formação do jovem quando se estuda a família e o trabalho e os fatores e meios de produção, respectivamente. Em cada semana de alternância é apresentado um Tema de Pesquisa.

$\mathrm{Na}$ pesquisa, foi utilizada a nomenclatura Tema Gerador, pois, em pesquisas recentes, estudiosos como Gnoato et al (2006), Pezarico (2014), entre outros, assim se referem aos Temas de Pesquisa. Da mesma forma, a ARCAFAR-SUL e as Casas Familiares Rurais do Estado do Paraná utilizam o termo Temas Geradores para designar os Temas de Pesquisa.

Entende-se que a partir destes Temas, os profissionais que atuam nos Ceffas possuem a tarefa de planejar e registrar os demais componentes de acordo com cada instrumento pedagógico ou disciplina do curso de formação.

Gimonet (2007) alerta que o exemplo que apresenta não é um modelo a ser seguido fielmente em todos os Ceffas. O importante, destaca o autor, é que os Temas Geradores sejam selecionados a partir de um estudo da realidade local, com base em diagnósticos participativos.

Ou seja, os Ceffas e as instituições que os coordenam podem orientar a construção do Plano de Formação de outras maneiras, desde que a realidade vivida pelo jovem seja considerada. Em primeiro lugar, deve-se perceber a realidade de vida dos jovens. Depois, "extrair os temas maiores, portadores de sentido em termos de atividades, ações, engajamentos e suportes para organizações didáticas" (GIMONET, 2007, p.77). Na sequência, estes temas devem ser colocados numa lógica progressiva de acordo com a capacidade de envolvimento e de aprendizagem do jovem. E, finalmente, as noções teóricas necessárias para que haja compreensão e desenvolvimento de mais capacidades por parte dos jovens devem ser inseridas.

A forma de organização dos conhecimentos no Plano de Formação é efetivada, portanto, por meio de Temas Geradores, que são temas próximos das situações familiares concretas dos jovens. Essa organização, embora anterior aos estudos de Paulo 


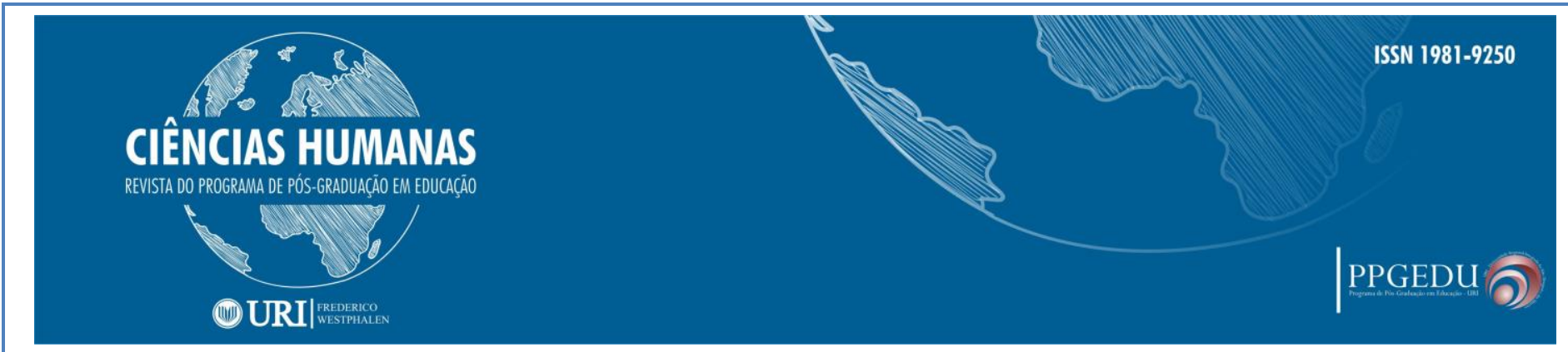

Freire, também nos remete ao pensamento deste autor. Gimonet (2007) cita Paulo Freire como um estudioso que presta grande contribuição para a Pedagogia da Alternância, sobretudo com sua obra "A educação como prática de liberdade" (1987).

Nesta obra mencionada por Gimonet (2007), Freire afirma que a dialogicidade é a essência da educação como prática de liberdade, entendida esta como uma educação que concebe o educando como sujeito da história, tendo o diálogo e a troca como traço essencial no desenvolvimento da consciência crítica para que possa romper com sua condição de oprimido. Assim, ele faz uma crítica à educação bancária que chama os educandos para apenas memorizar mecanicamente os conhecimentos que recebem do professor. Portanto, de forma vertical e antidialógica, a concepção bancária de ensino forma o educando para a passividade, para a acriticidade, e por isso é oposta à educação que pretenda educar para a autonomia.

a visão "bancária" da educação, o "saber" é uma doação dos que se julgam sábios aos que julgam nada saber. Doação que se funda numa das manifestações instrumentais da ideologia da opressão - a absolutização da ignorância, que constitui o que chamamos de alienação da ignorância, segundo a qual esta se encontra sempre no outro. O educador, que aliena a ignorância, se mantém em posições fixas, invariáveis. Será sempre o que sabe, enquanto os educandos serão sempre os que não sabem (FREIRE, 1987, p. 33).

O contrário da educação bancária é defendido por Freire (1987) como educação dialógica, que começa quando o educador se pergunta em torno do que vai dialogar com os educandos. Ou seja, a educação dialógica começa quando o educador reflete sobre quais são os conteúdos, os saberes escolares que devem ser tratados na escola. $\mathrm{O}$ conteúdo não pode ser tomado como uma doação ou uma imposição, "mas a devolução organizada, sistematizada e acrescentada ao povo daqueles elementos que este lhe entregou de forma desestruturada" (FREIRE, 1987, p. 47).

$\mathrm{O}$ autor, ainda, defende a ideia de que não se pode chegar aos camponeses e entregar-lhes conhecimento ou impor-lhes um modelo de homem, contido no programa cujo conteúdo foi planejado por pessoas que não possuem as vivências e expectativas dos camponeses.

Práticas dessa natureza tendem a falhar porque quem planeja parte de uma visão pessoal da realidade e não leva em conta os sujeitos em situação a quem se dirige seu \begin{tabular}{l|c|c|c}
\hline Rev. Ciências Humanas & Frederico Westphalen, RS & Vol. 19 n. 01 & jan./abr. 2018 \\
\hline
\end{tabular}

\begin{tabular}{l|l|l} 
Recebido em: 13/03/2017 & Aceito em: 20/04/2018 & Pg. 54 - 76
\end{tabular}




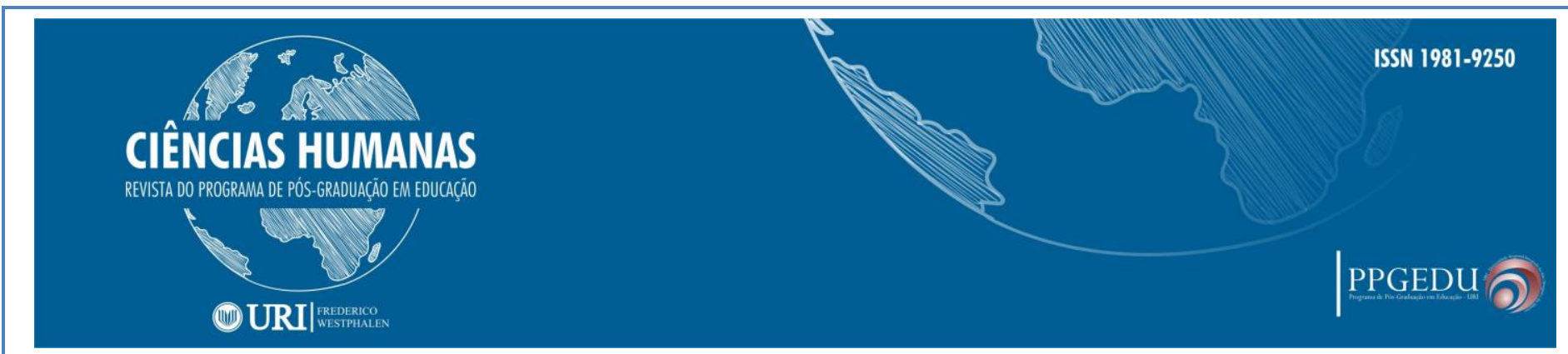

programa. Freire (1987) denomina essa prática de "invasão cultural". Será a partir da situação presente, existencial, concreta, refletindo o conjunto de expectativas dos sujeitos, que conteúdos programáticos para serem trabalhados na escola poderão se desenvolver.

É na realidade mediatizadora, na consciência que dela tenhamos, educadores e povo, que iremos buscar o conteúdo programático da educação. O momento deste buscar é o que inaugura o diálogo da educação como prática da liberdade. É o momento em que se realiza a investigação do que chamamos de universo temático do povo ou o conjunto de seus temas geradores (FREIRE, 1987, p. 50).

Os Temas Geradores para este autor são, portanto, a base para uma educação crítica, dialógica, que propõem ações coletivas que visam às mudanças do meio em que se vive. Eles refletem situações de desafio apresentadas aos jovens sobre a realidade em que estão inseridos; geralmente são análises de problemas cotidianos. Para Freire (1987), procurar um Tema Gerador é procurar o pensamento do homem sobre a realidade e sua ação sobre essa realidade. Na medida em que o ser humano toma uma atitude ativa na exploração de sua vivência, sua consciência crítica se aprofunda.

Como já afirmado anteriormente, na Pedagogia da Alternância, os Temas Geradores são construídos a partir de uma pesquisa participativa que envolve os jovens, família, monitores e a comunidade onde o Ceffa está inserido. Vários podem ser os encaminhamentos para esta pesquisa, como: reunião com a comunidade para que esta possa falar sobre os temas de interesse, visita aos familiares dos jovens para perceber quais são os temas de interesse, questionário enviado às famílias para que escrevam os temas de interesse, entre outros.

Com os Temas Geradores selecionados, inicia-se o trabalho de articulação com as atividades e os conteúdos previstos para a série, ciclo ou etapa. É tarefa dos monitores que trabalham nos Ceffas elaborar coletivamente o Plano de Formação, prevendo o que os jovens estudarão durante o período de formação, distribuindo os Temas Geradores e os conteúdos curriculares para cada período de alternância. 


\section{METODOLOGIA}

Minayo (1999) afirma que o que leva o pesquisador ao desenvolvimento da pesquisa e à produção do conhecimento é a existência do desconhecido no dia a dia. Com base neste pressuposto, a pesquisa nasceu, pois, do questionamento sobre como se produz um Plano de Formação, articulando Temas Geradores e conteúdos do Ensino Médio numa Casa Familiar Rural. Ou, tomando as palavras de Gimonet (2007), como reunir numa terceira lógica, duas lógicas complementares, mas muitas vezes contraditórias, que são a lógica da vida e a lógica dos programas escolares?

O Plano de Formação da CFR pesquisada foi cedido para análise e esta foi realizada a partir da elaboração três quadros que sintetizam a articulação entre Temas Geradores e conteúdos previstos para o Ensino Médio.

Para a elaboração destes quadros, levou-se em consideração os seguintes aspectos: as disciplinas foram organizadas por série, os Temas Geradores e os conteúdos foram copiados conforme constam no documento. Os dados apresentados referem-se às disciplinas de: Solos, Produção Animal, Horticultura, Produção Vegetal, Agroecologia (primeira série), Agroindústria (terceira série), Infraestrutura (terceira série), Administração Rural (primeira e segunda séries), Biologia (segunda e terceira séries), Química (primeira e segunda séries), Física (segunda e terceira séries), Matemática. Ou seja, não estavam disponíveis, no momento da pesquisa, os dados referentes a todas as disciplinas.

Após esta organização, retomou-se a questão: Como se articulam, na Casa Familiar de Cruz Machado - PR, Temas Geradores e conteúdos do Ensino Médio?

Objetivando responder a esta questão de pesquisa, foram estabelecidas três categorias que caracterizam a articulação entre Temas Geradores e conteúdos do Ensino Médio: articulação explícita, articulação implícita e articulação conforme a abordagem. De acordo com Minayo (1999), as categorias são empregadas para se estabelecer classificações. Nesse sentido, trabalhar com elas significa agrupar elementos em torno de um conceito capaz de abranger as ideias e expressões.

Assim, classificou-se como articulação explícita quando se conseguiu articular os Temas Geradores aos conteúdos direta e claramente, sem dúvida ou ambiguidade. Ou \begin{tabular}{l|c|c|c}
\hline Rev. Ciências Humanas & Frederico Westphalen, RS & Vol. 19 n. 01 & jan./abr. 2018 \\
\hline
\end{tabular}

\begin{tabular}{l|l|l} 
Recebido em: 13/03/2017 & Aceito em: 20/04/2018 & Pg. 54 - 76
\end{tabular}




\section{CIÊNCIAS HUMANAS}

REVISTA DO PROGRAMA DE PÓS-GRADUAĞ̈O EM EDUCAĞ̄o

\section{(1)URI|}

seja, quando os conteúdos foram escritos usando-se as mesmas palavras, sinônimos ou palavras relacionadas ao Tema Gerador.

De outra forma, classificou-se como articulação implícita quando os conteúdos possuem articulação com os Temas Geradores, mas não se apresentam com tanta clareza. Ou seja, quando se pode fazer relações, mas as palavras apresentadas não são as mesmas, nem sinônimas.

Quando a relação não foi percebida de nenhuma forma, utilizou-se a classificação “articulação conforme a abordagem". Ou seja, quando os conteúdos podem ser abordados pelos monitores de tal forma que uma relação possa ser construída com os Temas Geradores, mas que no documento esta articulação não aparece.

Para a apresentação desta classificação, optou-se por colocar nos quadros letras iniciais das categorias que sintetizam a articulação entre os Temas Geradores e os conteúdos previstos para o Ensino Médio, de acordo com a seguinte legenda:

\begin{tabular}{|c|}
\hline $\mathrm{CA}$ \\
\hline $\mathrm{AE}$ \\
\hline $\mathrm{AI}$ \\
\hline
\end{tabular}

Conteúdo que se articula com o Tema Gerador conforme a abordagem Conteúdo que se articula de forma explícita com o Tema Gerador Conteúdo que se articula de forma implícita com o Tema Gerador

Após essa classificação, o quadro foi analisado considerando a articulação existente entre Temas Geradores e conteúdos do Ensino Médio expressos nas DCEs (2008) e na Ementa do Curso Técnico em Agropecuária (2009), da CFR de Cruz Machado, no Estado do Paraná.

Ressalta-se que, ao tentar responder a questão de pesquisa, tem-se a clareza de que o produto final da análise deve ser sempre encarado de forma provisória e aproximativa, pois em se tratando de ciência, as afirmações podem superar conclusões prévias a elas e podem ser superadas por outras afirmações futuras (MINAYO, 1992).

Ou seja, as análises e discussões empreendidas a seguir correspondem a um contexto específico que está em constante processo de transformação e que não podem ser aplicadas a contextos distintos. 


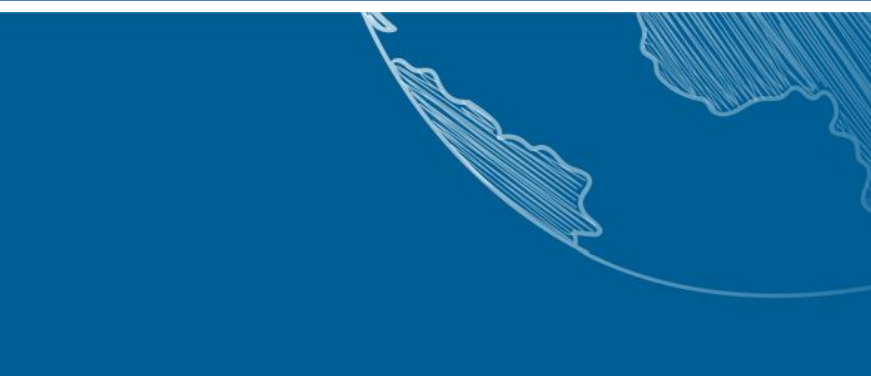

\section{RESULTADOS}

O Plano de Formação da Casa Familiar Rural de Cruz Machado se constitui em uma lista, organizada por série e por disciplina, de vinte Temas Geradores e os conteúdos para serem desenvolvidos em cada semana de alternância. Ressalta-se que cada Tema Gerador corresponde a uma semana de alternância.

O documento, mesmo estando disponível na Casa Familiar Rural para consulta da comunidade, não é publicado em suportes externos. O referido documento corresponde ao ano letivo de 2013, foi digitado e impresso em papel tamanho A 4, não apresenta cabeçalho e numeração das páginas.

É dividido por disciplinas, possui como título a série e a disciplina correspondente; seu conteúdo está diagramado em uma tabela que possui os seguintes campos: 1- Alternâncias; 2- Conteúdos. Abaixo desses campos, estão listados: 1- Temas Geradores e 2- Conteúdos que devem ser trabalhados em cada semana de alternância.

O Plano de Formação não apresenta elementos apresentados por Gimonet (2007), como a descrição das atividades que contemplam os conteúdos vivenciais, a saber: Colocação em Comum, Visita de Estudo, Colaborações Externas, Estágios, Atividades retorno/meio. Tais instrumentos pedagógicos, cujo objetivo é explorar os conteúdos vivenciais, não foram observados no Plano de Formação analisado, o que pode significar que, para os monitores, o estabelecimento dos Temas Geradores é suficiente para contemplar a vivência dos jovens.

Como mencionado anteriormente, a partir deste documento, foram elaborados quadros que sintetizam, a partir de categorias estabelecidas, a articulação ou não entre Temas Geradores e conteúdos previstos para o Ensino Médio ofertado pela Casa Familiar Rural de Cruz Machado.

A partir da análise dos quadros é possível quantificar os conteúdos previstos para cada etapa da formação que se articulam diretamente aos Temas Geradores (TGs), os que se articulam implicitamente e os que não possuem uma relação que possa ser vista imediatamente. Esta quantificação é apresentada no gráfico 1: 


\section{CIÊNCIAS HUMANAS}

REVISTA DO PROGRAMA DE PÓS-GRADUAĞ̈O EM EDUCAĞ̄o

\section{(1) URI|}

GRÁFICO 1 - Conteúdos articulados aos Temas Geradores (TGs), por série

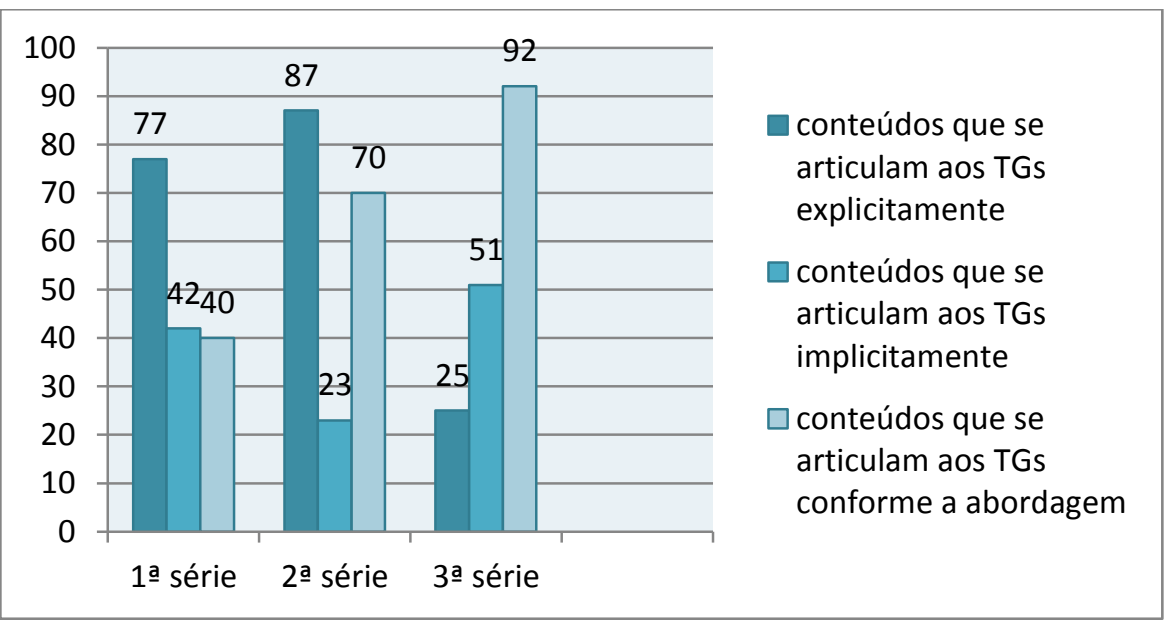

Fonte: Dados de pesquisa (2014)

Os dados demonstram que na $1^{\mathrm{a}}$ série foram analisados os conteúdos de oito disciplinas, em vinte semanas de alternância, perfazendo um total de 160 conteúdos elencados para trabalhar com os jovens nesta etapa da formação.

Destes 160 conteúdos, 77 se articulam explicitamente com os TGs apresentados, 42 se articulam de maneira implícita e 40 não demonstram articulação imediata com os TGs. Ou seja, aproximadamente $74,8 \%$ dos conteúdos trabalhados na $1^{\text {a }}$ série se articulam com os TGs e somente $25,2 \%$ dos conteúdos se articularão com TGs propostos se a abordagem do monitor assim permitir.

Nesta série não foi possível classificar 1 conteúdo porque o mesmo se refere a "conteúdo da ementa da disciplina", podendo este se articular explicitamente ou não ao TG proposto.

$\mathrm{Na} 2^{\mathrm{a}}$ série foram analisados os conteúdos de nove disciplinas também em vinte semanas de alternância, perfazendo um total de 180 conteúdos. Destes, 87 se articulam explicitamente com os TGs, 23 se articulam implicitamente e 70 não se articulam, à primeira vista, com os TGs. Ou seja, aproximadamente $61,1 \%$ dos conteúdos trabalhados na $2^{\mathrm{a}}$ série dizem respeito aos TGs propostos e $38,9 \%$ serão articulados aos TGs conforme a abordagem dada pelo monitor. 


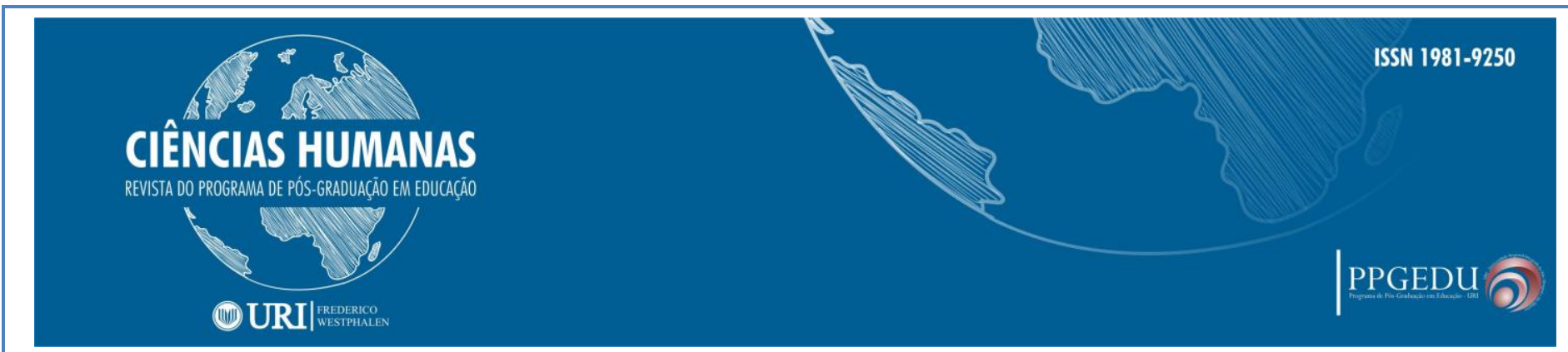

$\mathrm{Na} 3^{\mathrm{a}}$ série foram analisados os conteúdos de nove disciplinas em vinte semanas de alternância. A disciplina de Solos elencou apenas 9 conteúdos para serem desenvolvidos durante esta etapa da formação, sendo que em onze alternâncias não aparecem os conteúdos para serem desenvolvidos nesta disciplina. Como nesta série se trabalha com o Projeto Profissional de Vida do Jovem (PPVJ), pode-se entender que o monitor da disciplina de Solos trabalha especificamente com a construção deste. Também nesta série a disciplina de Infraestrutura não explicita o conteúdo que será trabalhado na última semana de alternância.

Portanto, foram analisados na $3^{\text {a }}$ série um total de 168 conteúdos. Destes, 25 se articulam explicitamente com os TGs, 51 se articulam implicitamente e 92 não apresentam articulação imediata com os TGs propostos para a série. Ou seja, aproximadamente $45,2 \%$ dos conteúdos trabalhados na $3^{\mathrm{a}}$ série se articulam com os TGs, enquanto que 54,8\% somente serão articulados se o monitor realizar uma abordagem adequada.

A observação deste quadro referente à $3^{\text {a }}$ série requer um olhar diferenciado porque nesta etapa a preocupação está centrada no Projeto Profissional de Vida do Jovem (PPVJ). Os Temas Geradores são, portanto, relacionados às fases de construção do Projeto, passando pelo tema, justificativa, cronograma, diagnóstico da propriedade, normas técnicas, embasamento teórico, viabilidade econômica, conclusão, elaboração e apresentação. São doze semanas de alternância para se desenvolver o PPJV e, percebese que, neste período, os monitores, excetuando aquele que atua na disciplina de Solos, continuam o trabalho com os conteúdos previstos nas DCEs e Ementa para dar suporte aos diversos Projetos que, com certeza, se referem a temáticas diferentes e que precisam de aporte teórico para serem desenvolvidas.

Percebe-se que nas $1^{\mathrm{a}}$ e $2^{\mathrm{a}}$ séries, em todas as alternâncias há pelo menos quatro disciplinas que desenvolvem conteúdos relacionados com os Temas Geradores. Isto não acontece na $3^{\text {a }}$ série pelo fato de que os 12 primeiros Temas Geradores desta série se referem ao PPVJ, a sua produção, formatação e apresentação. Somente a partir da décima terceira semana é que os temas que fazem parte da realidade dos jovens são retomados. 


\section{CIÊNCIAS HUMANAS}

REVISTA DO PROGRAMA DE PÓS-GRADUAĞ̈O EM EDUCAĞ̄o

\section{(10URI|}

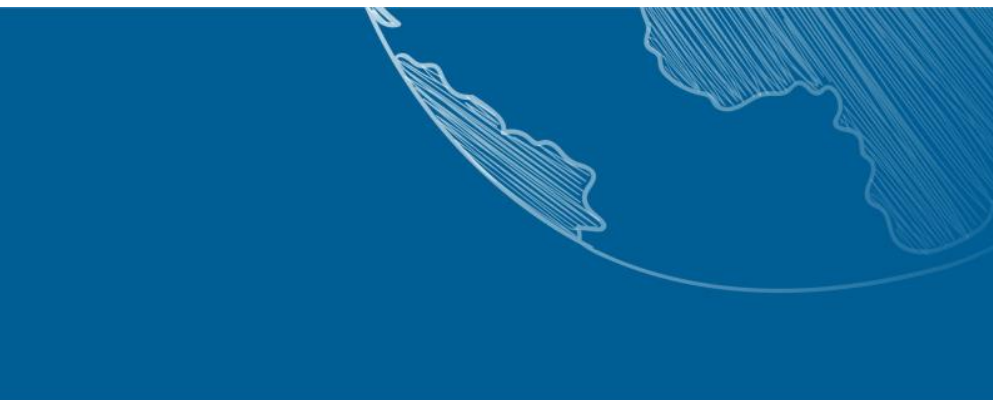

As disciplinas que menos demonstram conseguir estabelecer articulação entre seus conteúdos e os TGs são as de Matemática e Física, pertencentes à área de Ciências da Natureza, Matemática e suas Tecnologias. Porém, como afirmado anteriormente, o monitor pode fazer uma abordagem do conteúdo no momento em que está trabalhando de tal forma que os jovens consigam articulá-lo ao Tema Gerador.

Os quadros demonstram, ainda, que o Tema Gerador "Colheita e armazenagem e conservação de cereais", previsto para a $2^{\mathrm{a}}$ série, foi o único que, de uma maneira ou outra, os monitores conseguiram relacionar com os todos conteúdos das disciplinas analisadas.

Percebe-se que os TGs, a seguir, foram os que menos os monitores conseguiram relacionar com os conteúdos de suas disciplinas: $1^{\mathrm{a}}$ série - Turismo Rural; $2^{\mathrm{a}}$ série Manejo do pomar, Cooperativismo e associativismo, Culturas primárias, Ética e moral nas relações econômicas; $3^{\text {a }}$ série - Qualidade do leite, Plantas Medicinais, Sementes.

Observando-se os quadros de maneira vertical, é possível fazer a seguinte leitura: cada disciplina apresenta seus conteúdos de maneira organizada, tendo como referência os conteúdos expressos nas DCEs e Ementa do Curso. Um exemplo é a disciplina de Solos da $2^{\mathrm{a}}$ série, em que o conteúdo inicia com análise do solo, manejo e conservação, época de colheita, rotacionado de piquetes, vazio sanitário, cálculos de adubação e calagem, utilização de dejetos para adubação, fertilidade, aquisição de adubos em grupos, implantação de pastagens, sistemas de irrigação, acidez do solo, maximização do seu uso. Contudo, embora se perceba uma sistematização, os conteúdos não são apresentados de forma linear. Ou seja, são percebidos movimentos de retomada, de idas e vindas aos conteúdos ao longo do ano.

Outra observação realizada diz respeito ao desenvolvimento dos conteúdos das disciplinas no seguinte sentido: há conteúdos que precisam ser explorados durante mais de uma semana, pois possuem grande abrangência. Assim, não podem ser abordados apenas na semana que se articula explicitamente ao Tema Gerador.

Um exemplo que se destaca diz respeito à disciplina de Produção Animal, desenvolvida na $1^{\text {a }}$ série. Esta disciplina enfatiza a apicultura e propõe o trabalho com este tema durante seis semanas de alternância, porém inicia o trabalho quando o Tema 


\section{CIÊNCIAS HUMANAS}

REVISTA DO PROGRAMA DE PÓS-GRADUAĞ̈O EM EDUCAĞ̄o

\section{(10) URI|}

Gerador é "Pomar Caseiro" e estende-se passando pelas alternâncias que possuem os seguintes TGs: Saúde da Família, Preparo e conservação do solo, Apicultura, Diversificação da propriedade de culturas agrícolas alternativas, Introdução à vida profissional.

Analisando-se os quadros à luz dos conteúdos do Ensino Médio, expressos nas Diretrizes Curriculares Estaduais (2008) e na Ementa do Curso Técnico em Agropecuária (2009), percebe-se que os monitores fizeram uma escolha quando não conseguiram articular o Tema Gerador diretamente a um conteúdo da sua disciplina. Eles optaram por trabalhar os conteúdos previstos nestes dois documentos.

Percebe-se, portanto, que os conteúdos previstos nas DCEs e na Ementa do Curso foram contemplados. Esta observação pode ser feita tanto nas disciplinas da formação geral como nas disciplinas da parte técnica específica do curso.

Portanto, pela análise empreendida sobre o Plano de Formação, evidencia-se esforço por parte dos monitores em articular os Temas Geradores e os conteúdos previstos para o Ensino Médio, mas também dificuldade. Nem sempre é possível estabelecer uma articulação explícita e, quando realmente não se consegue, os conteúdos previstos nas DCEs e Ementa do Curso são priorizados. Contudo, não se descarta a possibilidade de uma abordagem diferenciada ser realizada em sala de aula para que os jovens percebam articulação dos conteúdos com os Temas Geradores.

Não foi possível realizar a análise dos conteúdos de todas as disciplinas. Portanto, os dados coletados demonstraram que, na maioria das vezes, os monitores, que atuam nas disciplinas em que foi possível fazer a análise, fazem uma articulação entre os Temas Geradores e os conteúdos do Ensino Médio. Destaca-se, porém, que esta articulação nem sempre é explícita. A forma como o conteúdo é abordado em sala de aula é que poderá fazer com que os monitores demonstrem a articulação existente entre conteúdos e Temas Geradores.

Para finalizar, reafirma-se que, no contexto da Casa Familiar Rural de Cruz Machado - PR, foi observado que o Plano de Formação é um documento considerado importante para organizar o processo pedagógico e que há preocupação e tentativa, por 


\section{CIÊNCIAS HUMANAS}

REVISTA DO PROGRAMA DE PÓS-GRADUAĞ̈O EM EDUCAĞ̄o

\section{(1) URI|}

parte dos monitores, em articular explicitamente os conteúdos vivenciais com os de formação geral e profissional.

Porém, verificou-se que articular, no Plano de Formação, Temas Geradores e conteúdos do Ensino Médio previstos nas DCEs e Ementa do Curso, é um grande desafio, pois, como afirma Gimonet (2007), são duas lógicas diferentes que precisam ser articuladas.

Uma lógica privilegia, ainda que recomende a contextualização dos conteúdos, a socialização do conhecimento científico, filosófico e artístico. Tais conhecimentos nem sempre possuem aplicação prática imediata, porém são importantes para "a formação necessária para o enfrentamento com vistas à transformação da realidade social, econômica e política de seu tempo" (DCES, 2008, p. 20). Esta lógica está pautada no entendimento de que os alunos que frequentam a escola pública pertencem à classe trabalhadora e que devem ter nela a oportunidade de acesso a tais conhecimentos, sob pena de não conseguirem esse acesso em outros espaços.

De outro turno, a lógica da Pedagogia da Alternância se assenta no trabalho com os conteúdos vivenciais, por entender que, desta forma, o jovem atribui sentido à sua aprendizagem, desenvolvendo seu interesse pelos estudos. São conteúdos que os jovens conseguem visualizar sua aplicação prática porque estão diretamente relacionados aos desafios enfrentados em seu dia a dia.

Entende-se que um ensino que valorize apenas os conhecimentos vivenciais em detrimento dos demais citados anteriormente forma o sujeito unilateralmente. Além disso, constitui-se como a negação de um direito, pois o ser humano, enquanto tal, pode e deve apropriar-se daquilo que foi produzido por outros humanos.

O desafio, portanto, se traduz em unir duas lógicas que apresentam concepções teórico-metodológicas diferenciadas, construídas em bases conceituais distintas, ao que se conclui, a partir da análise empreendida em uma realidade específica, que não é possível. 


\section{OCURI|}

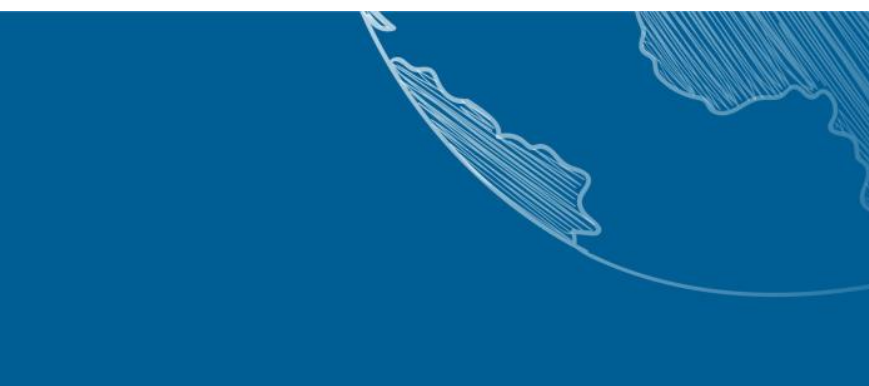

\section{CONSIDERAÇÕES FINAIS}

Este estudo teve como objetivo investigar como ocorre a articulação entre Temas Geradores e conteúdos do Ensino Médio no contexto da Pedagogia da Alternância, mais especificamente, no Plano de Formação elaborado na Casa Familiar Rural de Cruz Machado, Paraná.

Este Plano sistematiza as atividades e os conteúdos - vivenciais, formação geral e formação profissional - no que se refere à sequência das alternâncias e ao conjunto do percurso da formação do jovem. Cada sequência de alternância é dada por meio de um Tema Gerador que tem sua fonte nas atividades da vida (profissional, familiar, social) e que deve se articular às disciplinas do programa escolar oficial.

No Plano de Formação analisado percebeu-se que há a tentativa, por parte dos monitores, de articulação dos conteúdos gerais e da formação profissional com os Temas Geradores, porém nem sempre esta se apresenta de forma explícita. Ou seja, nem sempre é possível perceber a articulação entre os dois elementos mencionados, de forma clara, direta e objetiva.

Os dados revelaram que em todo período de formação, que compreende as três séries do Ensino Médio, 37,3\% dos conteúdos se articulam explicitamente com os Temas Geradores e $22,9 \%$ dos conteúdos se articulam implicitamente com os Temas Geradores.

Outras vezes, percebeu-se que os conteúdos do Ensino Médio poderão se articular com os Temas Geradores, se a forma de abordagem dos monitores permitir que a devida articulação seja realizada. Portanto, a forma de conduzir o trabalho, de contextualizar e exemplificar os conteúdos pode fazer a diferença na efetivação da proposta feita pela Pedagogia da Alternância.

Os dados revelaram que, em todo o período de formação de jovens, 39,8\% dos conteúdos se articularão com os Temas Geradores a depender da abordagem realizada em sala de aula.

Não se quer dizer com isso que a efetivação desta Pedagogia depende única e exclusivamente dos monitores, pois são vários os elementos que determinam a prática realizada. Estes elementos são relacionados a diversos fatores que envolvem questões 


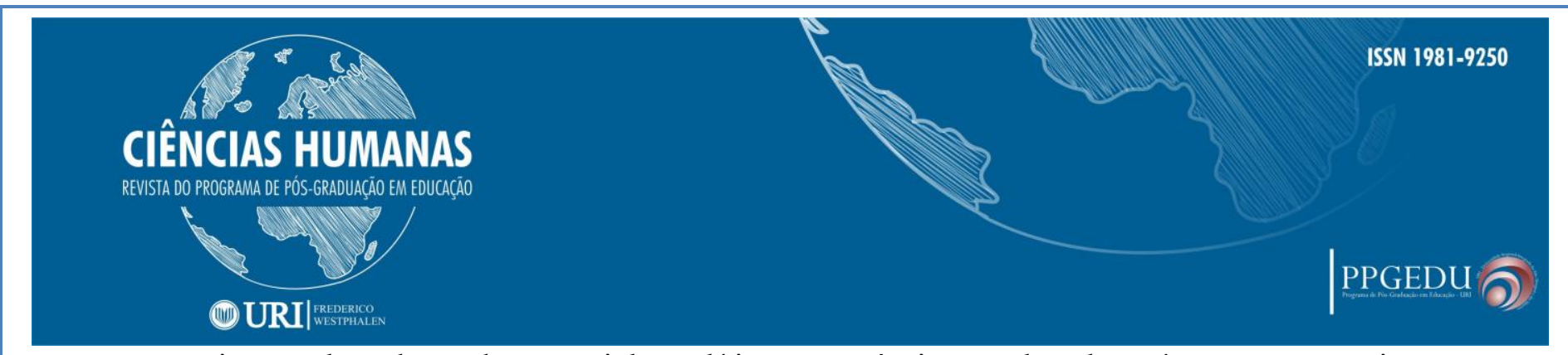

mais amplas de ordem social, política, econômica, cultural, até questões mais específicas, como as relacionadas à formação dos monitores, conhecimento da proposta, relações estabelecidas no interior da Casa Familiar Rural e desta com a Secretaria de Estado da Educação, com o Núcleo Regional de Educação, com a Associação Local, com a Arcafar-Sul e com a comunidade.

Enfim, enfrentar o desafio de articular os Temas Geradores e os conteúdos do Ensino Médio requer o entendimento de que estes dois elementos são decorrentes de concepções diferentes e, portanto, muitas vezes, contrárias. Sem essa reflexão, corre-se o risco de se realizar uma articulação artificial, apenas para cumprir o estabelecido.

Em outras palavras, quando não há a articulação entre os conteúdos vivenciais e os de formação geral e profissional, os jovens podem receber uma formação que não atenda às suas necessidades e, principalmente, não respeite seu direito de ter acesso ao conhecimento.

Enfim, a proposta da Pedagogia da Alternância de integrar os saberes vivenciais e os formais, não foi totalmente observada na realidade pesquisada. Os conteúdos que estão no Plano de Formação da Casa Familiar Rural de Cruz Machado e que não se articulam explicita nem implicitamente com os Temas Geradores correspondem a $39,8 \%$ do total de conteúdos. Isto equivale a um período inteiro de formação, ou seja, equivale ao número de conteúdos que podem ser abordados em uma série do Ensino Médio.

A partir deste dado, pode-se inferir que um terço da formação dos jovens, neste momento, na CFR pesquisada, acontece, aparentemente, sem a criação de vínculo com sua vida e trabalho no campo. Portanto, a prática realizada na Casa Familiar Rural de Cruz Machado, no que se refere à produção do Plano de Formação, pode ser considerada como um processo que muito tem a avançar para garantir ao jovem uma educação que alie sua experiência aos conhecimentos de formação geral e profissional.

Espera-se que este estudo possa incentivar novas análises e servir de material para a reflexão de monitores e demais sujeitos que atuam direta ou indiretamente em Centros Familiares de Formação por Alternância. Afinal, esses profissionais possuem não só a tarefa de produzir um Plano de Formação que garanta aos educandos o acesso aos 
conhecimentos expressos no currículo oficial, mas também de igualmente atender às especificidades da Pedagogia da Alternância.

\section{REFERÊNCIAS}

ARCAFAR-SUL. Associação Regional das Casas Familiares Rurais do Sul do Brasil. Histórico da Arcafar. Disponível em: 〈http://www_arcafarsul.gov.br〉. Acesso em: 22. jun. 2013.

CASA FAMILIAR RURAL DE CRUZ MACHADO. Ementa do Curso Técnico em Agropecuária. Cruz Machado, 2009.

CASA FAMILIAR RURAL DE CRUZ MACHADO. Plano de Formação. Cruz Machado, 2013.

ESTEVAM, Dimas Oliveira. Casa Familiar Rural: a formação com base na pedagogia da alternância. Florianópolis: Insular, 2012.

FREIRE, Paulo. Pedagogia do Oprimido. 17 ed. Rio de Janeiro: Paz e Terra, 1987.

GIMONET, Jean Claude. Praticar e Compreender a Pedagogia da Alternância dos CEFFAs. Petópolis, RJ: Vozes, Paris: AIMFR - Associação Internacional dos Movimentos Familiares e de Formação Rural, 2007.

GNOATTO, Antonio A. et al. Pedagogia da alternância: uma proposta de educação e desenvolvimento no campo. In: XLIV Congresso da Sober: questões agrárias, educação no campo e desenvolvimento. Fortaleza: Sociedade Brasileira de Economia e Sociologia Rural, 2006.

MARIRRODRIGA, Roberto Garcia; CALVÓ, Pedro Puig. Formação em Alternância e desenvolvimento local: o movimento educativo dos CEFFA no mundo. Argentina: Colección AIDEFA, 2010.

MINAYO, Maria Cecília de Souza. O Desafio do Conhecimento: pesquisa qualitativa e, saúde. São Paulo-Rio de Janeiro, HUCITEC-ABRASCO, 1992.

MINAYO, Maria Cecília de Souza. Pesquisa Social: teoria, método e criatividade. 14 ed. Petrópolis: Vozes, 1999.

PARANÁ. SECRETARIA DE ESTADO DA EDUCAÇÃO. Diretrizes Curriculares para a Educação Básica. Curitiba: SEED, 2008. 


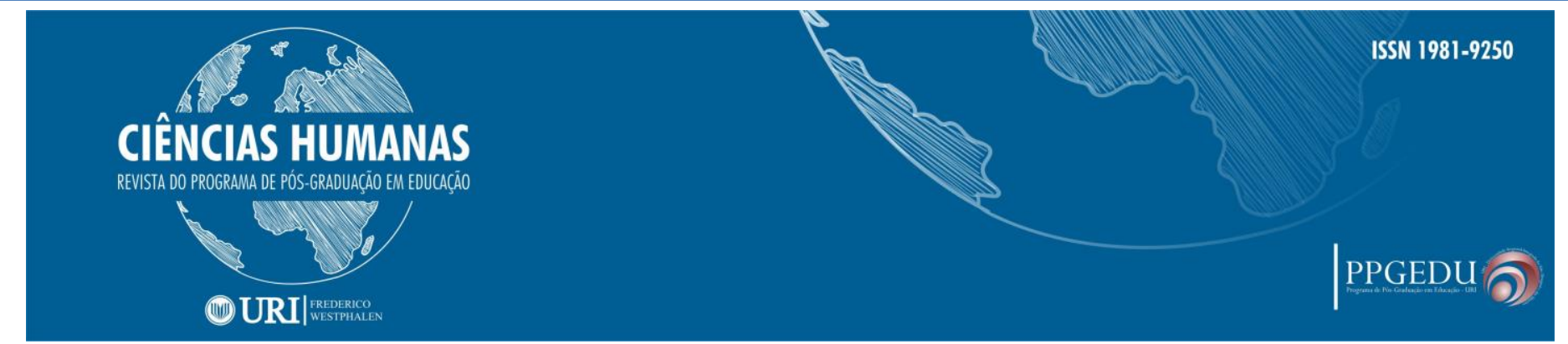

PEZARICO, Geovana. A casa, a terra e o mar: os objetos e os espaços no contexto da pedagogia da alternância. 2014. 201f. Tese (Doutorado). Universidade Tecnológica Federal do Paraná, Curitiba, 2014.

UNEFAB. União Nacional das Escolas Famílias Agrícolas do Brasil. Disponível em: <http://www.unefab.org.br>. Acesso em: 28. abr. 2013. 